\title{
Malignant Arterial Hypertension Revealing Focal Segmental Hyalinosis
}

\author{
N Mahoungou Mackonia*, A Maslouhi, T Elongo, S Arous, G Benouna, A Drighil, L Azzouzi and R Habbal \\ Department of Cardiology, Nephrology, Ophthalmology, Chu-ibn ROCHD, Morocco
}

Submission: August 23, 2021; Published: September 14, 2021

*Corresponding author: Noël Maschell Mahoungou-Mackonia, Department of Cardiology, ibn ROCHD University Hospital, Morocco

Abstract

Malignant arterial hypertension (MAH) is a hypertensive emergency associated with grade III or IV retinopathy. Focal segmental hyalinosis (FSH), of late onset, is one of its rare entities, with an incidence of 7 per million, responsible for $15-20 \%$ of nephrotic syndromes in adults. We report a case of segmental and focal hyalinosis in a 27-year-old patient with no previous history of malignant hypertension, who consulted us for neurosensory signs and ocular redness. The clinical examination showed a hypertensive peak at $240 / 150 \mathrm{~mm} \mathrm{Hg}$ with myocardial hypertrophy confirmed by electrocardiogram and transthoracic echo. A fundus examination completed by an optical coherence tomography revealed a KIRKENDAL stage III retinopathy associated with an occlusion of a branch of the central retinal vein. An impure nephrotic syndrome associated with renal failure was observed. A biopsy of a fragment of renal parenchyma supplemented by pathology was performed in favour of FH with chronic tubulointerstitial disease. The patient was managed urgently with nicardipine $3-5 \mathrm{mg} / \mathrm{hr}$ by electric syringe within 24 hours, followed by a triad of antihypertensive drugs consisting of amlodipine, indapamide and Ramipril at full dose combined with prednisone $60 \mathrm{mg} / \mathrm{day}$ for 4 months with a 6 month taper. The evolution was marked by a normalisation of the renal function, disappearance of the proteinuria and even a normalisation of his eye fundus after one year. FSH constitutes a group of heterogeneous pathologies with multiple causes, of which malignant hypertension is a secondary one, requiring not only symptomatic but also etiological management.

Keywords: Malignant arterial hypertension; Focal segmental hyalinosis

Abbreviations: MAH: Malignant Arterial Hypertension; FSH or FH: Focal Segmental Hyalinosis; BP: Blood Pressure

\section{Introduction}

Malignant arterial hypertension (MAH) is a nosological entity defined by an abrupt rise in blood pressure $(B P>180 / 110 \mathrm{~mm}$ $\mathrm{Hg}$ ) associated with grade III or IV retinopathy [1]. It is a hypertensive emergency with a poor prognosis, which has become exceptional nowadays in countries with adequate medical coverage [2]. Malignant hypertension causes multivisceral failure as a result of ischaemia secondary to multiple lesions in the vascular endothelium. Focal segmental glomerulosclerosis, which occurs later than retinal and cerebral damage [1], is one of its consequences. This entity is rare with an incidence of 7 per million, responsible for 15 to $20 \%$ of adult nephrotic syndromes [3]. We report a case of segmental and focal hyalinosis in the setting of malignant hypertension.

\section{Case Report}

We report the case of a 27 year old patient, with no particular personal or family history and a body mass index of $23 \mathrm{~kg} /$ $\mathrm{m}^{2}$, hospitalized in the cardiology department for malignant hypertension (hypertension). The diagnosis was made in the presence of headaches, dizziness, palpitations, ocular redness and a sudden drop in visual acuity, which led to a consultation in ophthalmology. The clinical examination revealed a hypertensive peak of $240 / 150 \mathrm{~mm} \mathrm{Hg}$ with a heart rate of 70 beats/min and discrete oedemas of the lower limbs, whitish in colour, taking the cup. left ventricular hypertrophy was found on electrocardiogram confirmed by transthoracic echocardiography (SIV/VGTD $=13 \mathrm{~mm}$; $\mathrm{PP} / \mathrm{VGTD}=13 \mathrm{~mm}$ ). A workup was performed, including a fundus, 


\section{Juniper Online Journal of Case Studies}

supplemented by an optical coherence tomography (OCT) scan, showing bilateral papilledema; central hemorrhage predominantly in the left eye; macular edema more to the right and occlusion of a branch of the central vena mater. The biological work-up showed an impure nephrotic syndrome with 24-hour proteinuria at $6.6 \mathrm{~g} / 24 \mathrm{~h}$, microscopic haematuria $(15,000 \mathrm{red}$ blood cells/field) on cytobacteriological examination of the urine, renal failure at $23.5 \mathrm{mg} / \mathrm{l}, \mathrm{GFR}$ at $35.5 \mathrm{ml} / \mathrm{mn} / \mathrm{m}^{2}$ and urea at $0.81 \mathrm{~g} / \mathrm{l}$ with hypo albuminemia at $27 \mathrm{~g} / \mathrm{l}$ and hypo complement $\mathrm{C} 3$ at $0.25 \mathrm{~g} / \mathrm{l}$ and hypertriglyceridaemia at $3 \mathrm{~g} / \mathrm{l}$. A biopsy of a fragment of the renal parenchyma, completed by a pathological assessment, was carried out in favour of a focal segmental hyalinosis (FSH) with chronic tubulointerstitial damage. The workup for secondary FH was normal, including: methoxylate levels, thyroid hormones, plasma renin, blood aldosterone, blood cortisol, blood glucose, complete serology and complete immunology. Abdominal ultrasound, renal artery Doppler and renal bladder ultrasound were normal as was the abdominopelvic CT scan. The diagnosis of FSH probably secondary to malignant hypertension was made. The patient was admitted to hospital as an emergency, conditioned with monitoring ; Loxen at $3 \mathrm{mg} / \mathrm{hr}$ to $5 \mathrm{mg} / \mathrm{hr}$ by electric syringe over $12 \mathrm{hrs}$ with an increase of $0.5 \mathrm{mg} / 15 \mathrm{~min}$ was administered, then relayed by amlodipine $10 \mathrm{mg} /$ day, Ramipril $10 \mathrm{mg}$ /day and bisoprolol $2.5 \mathrm{mg} /$ day. Atorvastatin was administered at $40 \mathrm{mg} / \mathrm{dr}$ followed by corticosteroid therapy with prednisone $60 \mathrm{mg} / \mathrm{dr}(1 \mathrm{mg} / \mathrm{Kg} /$ dr) for 4 months with gradual taper for 6 months combined with vitamin $\mathrm{D}$, calcium, potassium supplementation and gastric dressing with pantoprazole $30 \mathrm{mg} / \mathrm{dr}$ were administered. The patient was admitted to hospital for one week and then discharged with a blood pressure of $130 / 70 \mathrm{mmHg}$ with close monitoring for 1 year. The evolution is marked by an improvement in visual acuity, neurosensory signs and a balance in blood pressure. On the biological level, there was an improvement in renal function (creatinine level at $12 \mathrm{mg} / \mathrm{l}$ with a GFR of $77 \mathrm{ml} / \mathrm{mn}$ ) with disappearance of the $0.2 \mathrm{~g} / \mathrm{l}$ proteinuria and an improvement in his eye fundus.

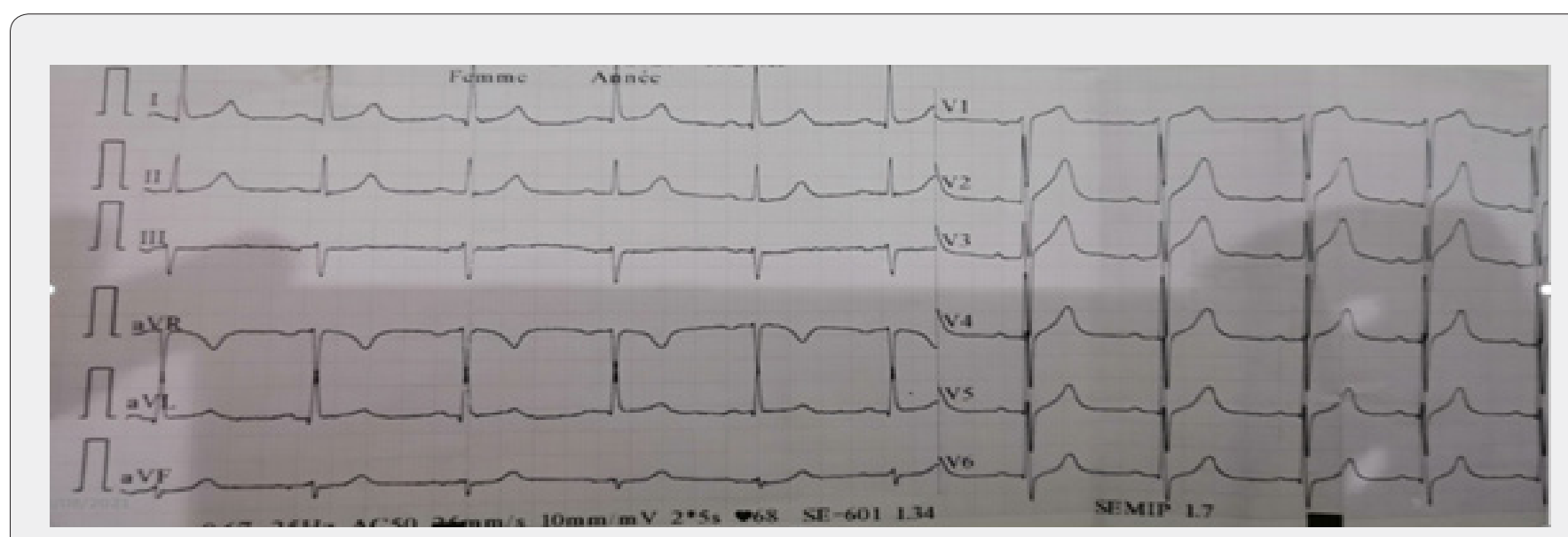

Figure 1: 12-lead ECG in a 27 -year-old patient with $28 \mathrm{~mm}$ left ventricular hypertrophy by the Cornell method.

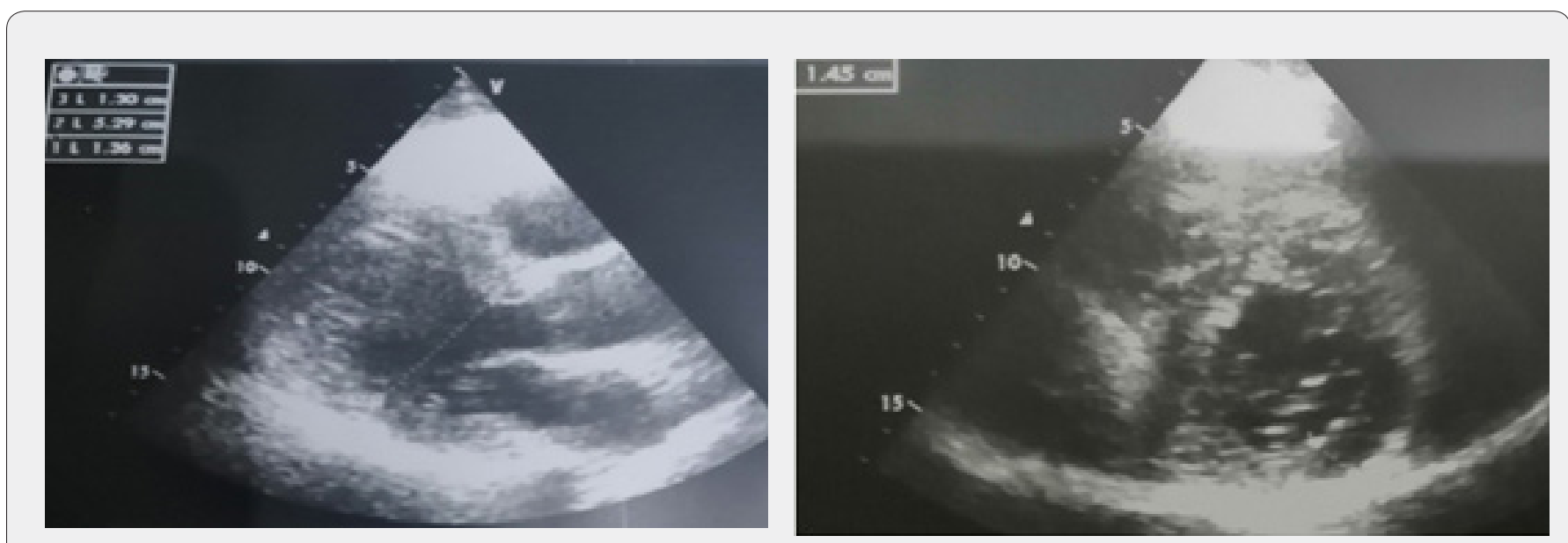

Figure 2: Hypertrophy of the left ventricle as seen on parasternal long and short axis sections. 


\section{Juniper Online Journal of Case Studies}
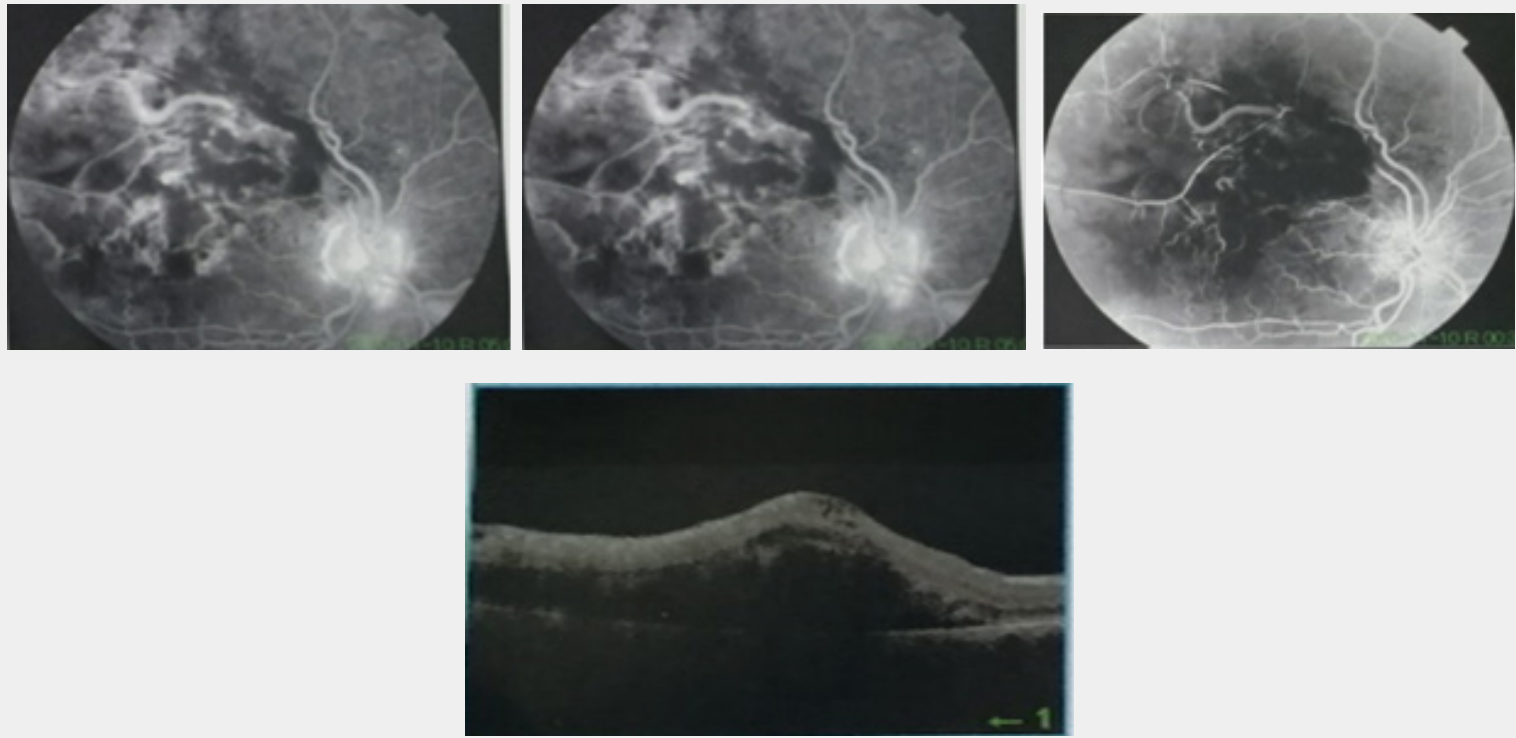

Figure 3: Fundus showing right papilledema, central haemorrhage, macular oedema on the right, occlusion of a branch of the Central Retinal Vein.
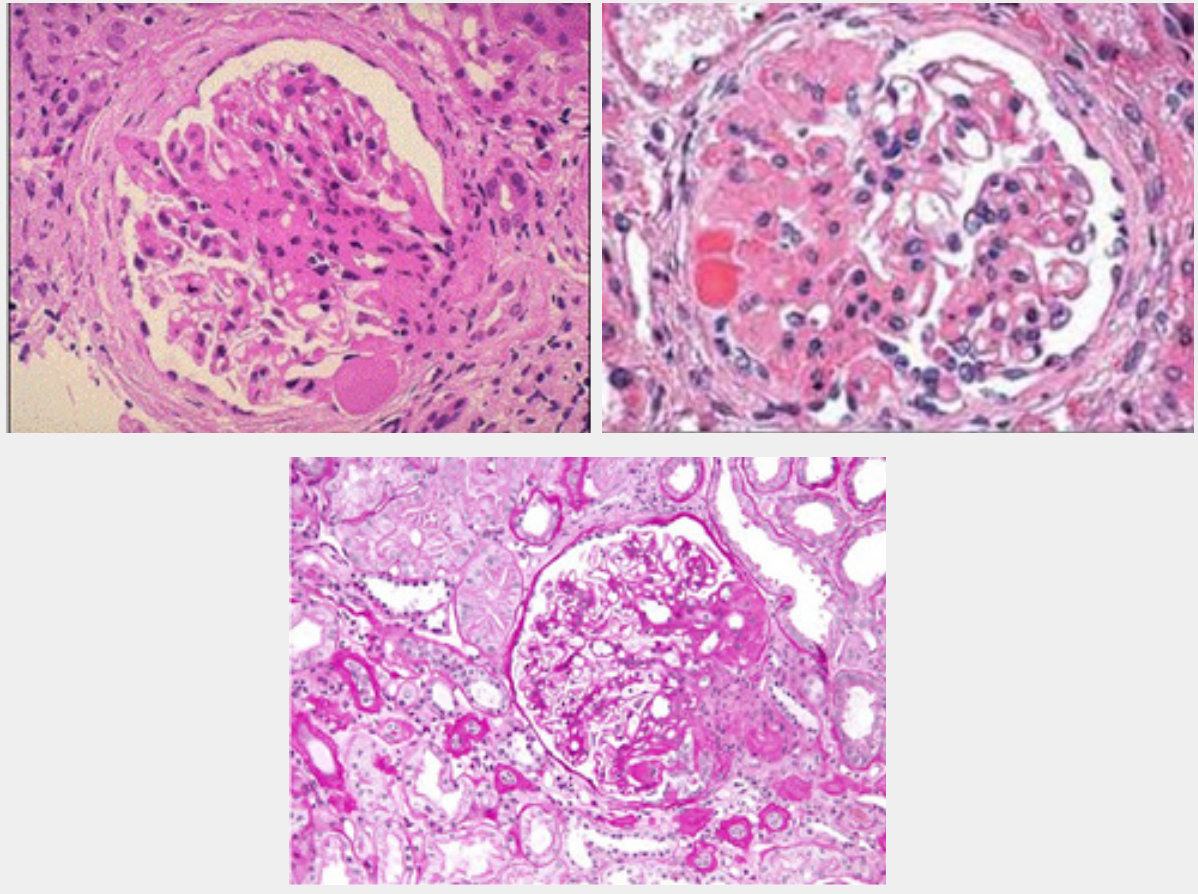

Figure 4: Focal segmental hyalinosis after pathological analysis of a renal biopsy.

\section{Discussion}

Focal segmental hyalinosis (FSH) is a rare kidney disease with an incidence of 7 per million. It affects both children and adults with peaks at 6-8 and 20-30 years of age, respectively [3]. FSH is the leading cause of nephrotic syndrome in the United States (accounting for approximately 35\% of cases). It is somewhat less common in Europe, $12 \%$ in Spain. In 2010, in France, $2.2 \%$ of incident patients with end-stage renal disease have FSH (Kidney Registry 2010) [4,5]. FSH is responsible for $15-20 \%$ of adult nephrotic syndromes [3]. The onset of nephrotic syndrome in $\mathrm{FH}$ is due to a disturbance of renal function because of glomerular damage and scarring. The disease is due not only 
to glomerular sclerohyaline lesions which may be associated with immunological deposits (IgM, C3) within these lesions, but also to podocyte damage, resulting in the loss of the physical integrity of the filtering barrier. A protein produced by podocytes, called integrin $\alpha v \beta 3$, is crucial in 'gluing' podocytes to the structure of the glomeruli.

Dysregulation of the $\alpha v \beta 3$ integrin pathway could lead to glomerular filtration dysfunction. Damaged glomeruli allow the passage of large molecules, especially proteins. Nephrotic syndrome is often impure, i.e. associated with hypertension and/ or haematuria and/or organic renal failure $[3,6,7]$.

FSH may be primary without any cause found, in which case, $\mathrm{AH}$ progressively sets in with the renal disease thus worsening the prognosis, or it may be secondary in relation to several pathologies including viral, drug-induced, genetic, $\mathrm{AH}$, etc.; in this case, $\mathrm{AH}$ precedes the clinical picture $[4,7]$. Thus, malignant hypertension can cause a variety of lesions, including glomerular endothelial and epithelial cell damage, glomerular hyperfiltration, increased renin-angiotensin-aldosterone system, and endothelialepithelial interaction, leading to the development of secondary FSH and proteinuria, but less so than in the primary forms $[7,8]$. Only a few clinical studies describe the development of FSH in malignant hypertension and these studies have reported that it can occur in primary malignant hypertension with nephrotic-like proteinuria, and may contribute to renal dysfunction [8]. Early treatment of hypertension is essential with a blood pressure target of $130 \mathrm{mmHg}$ systolic and $80 \mathrm{mmHg}$ diastolic for patients with significant proteinuria $>1 \mathrm{~g} / 24 \mathrm{~h}$. High-dose corticosteroid therapy is the first-line treatment of choice in primary $\mathrm{FH}$ [9]. But the rare genetic forms are rather cortico-resistant [7].

Our patient was 27 years old, the age favorable for peak $\mathrm{FH}$ as reported in the literature. He presented with FH secondary to malignant $\mathrm{AH}$, which can be explained by a very prominent and prominent $\mathrm{AH}$, rarely seen in primary $\mathrm{FH}$. Although no etiology of malignant $\mathrm{AH}$ was found in our patient, the evolution was marked by an improvement of the clinical picture under 3 antihypertensive drugs and corticotherapy.

\section{Conclusion}

Malignant hypertension is a serious disease with several complications including FSH. The aetiologies are multiple and must be found. The management must be done urgently because it conditions the vital prognosis of the patient.

\section{Consent}

In accordance with international or academic standards, the patient's written consent has been collected and retained by the author(s).

\section{References}

1. J Demiselle, F Beloncle, P Asfar, N Lerolle (2015) Malignant arterial hypertension. SRLF and Lavoisier SAS 24: 165-171.

2. Gazzah M (2018) Hypertension.

3. Centre hospitalier universitaire de (2021) Segmental and Focal Hyalinosis (SFH).

4. Beaudreuil S, Durrbach A (2017) Segmental and focal hyalinosis (SFH). Bull Acad Natle Méd 1 : 47-69.

5. Rivera F, Gomez JML, Garcia RP (2004) Clinicopathologic correlations of renal pathology in Spain. International Society of Nephrology 66(3): 898-904.

6. Idiopathic nephrotic syndrome. Nephrotic Syndrome Reference Centre. National Protocol for Diagnosis and Care, 5 November 2014.

7. M. Ghali, S Aloui, A Letaief, M Hamoud, H Skhiri, et al. (2015) Profile of arterial hypertension in segmental and focal hyalinosis. Tunisia Annals of Cardiology and Aneiology 64(3): 00033928.

8. Fukuda K, Shimizu A, Kaneko T, Masuda Y, Yasuda F, et al. (2013) A case of secondary focal segmental glomerulosclerosis associated with malignant hypertension. Japanese Society of Nephrology 2(1): 68-75.

9. Canaud G (2012) Segmental and focal hyalinosis and transplantation. Le Courrier de la Transplantation, Vol. 12.

\section{Your next submission with Juniper Publishers will reach you the below assets}

- Quality Editorial service

- Swift Peer Review

- Reprints availability

- E-prints Service

- Manuscript Podcast for convenient understanding

- Global attainment for your research

- Manuscript accessibility in different formats

( Pdf, E-pub, Full Text, Audio)

- Unceasing customer service

Track the below URL for one-step submission

https://juniperpublishers.com/online-submission.php 